\title{
Recepção da obra do poeta Fernando Pessoa em periódicos de \\ Belém do Pará
}

\author{
Reception of the work of the poet Fernando Pessoa in periodicals of Belem do Pará
}

Maria de Fátima do NASCIMENTO*

Universidade Federal do Pará (UFPA)

RESUMO: O presente trabalho objetiva trazer à baila a recepção da obra de Fernando Pessoa (1888-1935) em quatro periódicos de Belém do Pará nas décadas de 1940 e 1950. Trata-se de alguns poemas publicados em $1^{\circ}$ de dezembro de 1946 no "Suplemento Arte Literatura" da Folha do Norte e de outros estampados no segundo semestre de 1948 na Revista Encontro, coordenada por Benedito Nunes. Do vate lusitano há no "Suplemento" uma pequena coletânea de cinco poemas organizada pelo professor de Literatura Francisco Paulo Mendes, coletânea esta reeditada em 1948 na Revista Encontro, demonstrando que Fernando Pessoa era lido no Pará por sua Geração Moderna de 1946, a qual Benedito Nunes integrou, tendo posteriormente escrito artigos a respeito do poeta luso para o jornal A Província do Pará, a partir dos anos de 1957.

PAlAVRAS-ChAVE: Fernando Pessoa. Poesia. Recepção crítica. Periódicos do Pará. Benedito Nunes.

ABSTRACT: The present work objetives bring to light the reception of Fernando Pessoa's work (1888-1935) in periodicals of Belém do Pará in the 1940s and 1950s. These are poems published on December 1, 1946 in the "Suplemento Arte Literatura" of Folha do Norte and others printed on the second half of 1948 in Revista Encontro, coordinated by Benedito Nunes. There is a small collection of five poems from the Lusitanian in the "Suplemento" organized by the professor of Literature Francisco Paulo Mendes, collection that was reissued in 1948 Revista Encontro, demostrating that Fernando Pessoa was read in Pará by Modern Generation of 1946, which Benedito Nunes joined and later wrote articles about the Portuguese poet for the newspaper The Province of Pará, from the years of 1957.

KEYWORDS: Fernando Pessoa. Poetry. Crítical reception. Newspaper from Pará. Benedito Nunes.

\footnotetext{
* Doutora em Teoria e História Literária pela UNICAMP e Professora de Literatura Brasileira na UFPA. E-mail: fatimanascimentoletrasead@hotmail.com Revista Moara, n. 52, jan-jul 2019 ISSN: 0104-0944 


\section{Introdução}

Em 1946, em Belém do Pará, poemas de Fernando Pessoa (1888-1935) foram estampados no "Suplemento Arte Literatura" do jornal Folha do Norte, Suplemento este orientado por Haroldo Maranhão, neto do dono do periódico, bem como em 1948, na Revista Encontro, dirigida por Benedito Nunes, Mário Faustino e Haroldo Maranhão. Tais publicações demonstraram que, muito próximo da divulgação da obra do vate português, em 1942, dela houve a recepção em Belém (PA), num momento da formação de quatro autores, que leram semelhante obra e com ela aprenderam: Benedito Nunes, Max Martins, Mário Faustino e Haroldo Maranhão. Assim sendo, o presente trabalho surgiu tendo em vista examinar a recepção de Fernando Pessoa (1888-1935) em periódicos belenenses das décadas de 1940 e 1950: o aludido "Suplemento Arte Literatura" da Folha do Norte, a Revista Encontro e o jornal A Província do Pará.

Ali, composições pessoanas começaram a ser divulgadas pelo Professor de Literatura Brasileira e Portuguesa Francisco Paulo Mendes (1910-1999), que, na capital do estado em tela, lecionava em vários colégios particulares, como o Nossa Senhora de Nazaré, e públicos, como o Colégio Paes de Carvalho, sendo considerado, por Benedito Nunes, Haroldo Maranhão e Max Martins, o mentor do grupo que conviveu com ele no Café Central, ponto de encontro literário dos referidos literatos do período. Posteriormente, o mesmo mestre passa a lecionar na Universidade Federal do Pará (UFPA).

\section{Francisco Paulo Mendes: o professor do jovem Benedito Nunes}

De acordo com o poeta Max Martins, foi o Professor Francisco Paulo Mendes quem divulgou o Modernismo na década de 1940 entre os versejadores da Academia dos Novos, uma associação que congregava jovens como Benedito Nunes, Haroldo Maranhão e Max Martins, os quais até 1945, igualmente aos seus dois pares, ainda se encontravam escrevendo poemas parnasianos. Conforme palavras do último vate aludido:

Primeiro só ouvi falar de seu nome, Francisco Paulo Mendes, professor de Literatura do Colégio Nazaré. Um aluno seu, a quem mostrara alguns dos meus poemas, ainda metrificados e rimados, de acordo com o figurino do Tratado de Versificação de Olavo Bilac e Guimarães Passos, disse: "o professor Mendes nos ensinou que, em 1922, houve a Semana de Arte Moderna em São Paulo. O verso já estava livre e o poeta não precisava mais contar as sílabas nem rimar direitinho os sonetos, obrigatoriamente (MARTINS, 2001, p, 75).

A contar de 5 de maio de 1946, quando o "Suplemento Arte Literatura" do jornal 
Folha do Norte saiu às ruas de Belém do Pará, aos domingos, Benedito Nunes e os dois amigos literatos, mais ou menos da mesma idade, já que Mário Faustino só chegou ao grupo no ano seguinte, passaram a colaborar em tal caderno cultural, juntamente com Francisco Paulo Mendes, que, a partir deste momento leu e discutiu poemas dos jovens, orientando-os. De acordo com Max Martins:

Chico Mendes além de professor, era crítico de literatura e arte, tendo publicado artigos e ensaios em vários jornais e revistas do Pará, mas se dizia ser unicamente professor. Nosso mestre, e que, efetivamente, foi tornando-se o líder do nosso grupo, da nossa geração.

E líder de geração da "roda" do Café Central. Ali ele tomava o seu chá com torradas e nos ensinava-nos literatura, falava sobre artes plásticas, da poesia de Rilke, do Simbolismo, do Modernismo, de romances, teatro e questionava tudo. [...] (MARTINS, 2001, p, 75-76).

Tal mestre publicou doze textos entre artigos críticos e seleção de poemas no "Suplemento Arte Literatura" (NASCIMENTO, 2012, p. 523-524), iniciando a atividade no dia 19 de maio de 1946 e encerrando-a no dia $1^{\circ}$ de janeiro de 1949 . Dos doze textos estampados no encarte jornalístico, cinco versaram sobre poetas lusitanos, de nomes a serem conhecidos mais à frente.

No dia 16 de junho de 1946, Francisco Paulo Mendes iniciou a divulgação de literatos lusitanos na Folha do Norte, numa seção de crítica, espécie de coluna intitulada "Poetas Portugueses Contemporâneoas”, que começou com José Régio (1901-1969), integrante do Segundo Modernismo Luso ou Geração Presença. Na sequência, teve-se Fernando Pessoa em 30/06/1946, Florbela Espanca (1894-1930) em 14/07/1946, Alberto de Serpa (1906-1992) em 28/07/1946 e Antonio Feijó (1859-1917) em $7 / 09 / 1946^{1}$.

Em 30 de junho de 1946, Francisco Paulo Mendes publicou o seu primeiro artigo analisando a obra de Fernando Pessoa. No final do texto, foi estampado o poema “Aniversário", de um heterônimo de Fernando Pessoa, Álvaro de Campos. Conforme o primeiro parágrafo do artigo:

Fernando Pessoa foi um caso excepcional na literatura portuguesa. Um grande poeta e, também, a mais estranha figura de escritor que apareceu neste século em Portugal. Costumava dizer de si que, artisticamente, não sabia senão mentir. Confessava-se um simulador e um mistificador e proclamava que a sua obra era toda feita apenas de "atitudes literárias". Mas é por meio de uma dessas suas desconcertantes expressões prediletas - "Fingir é conhecer-se" - que nós vamos penetrar no segredo da mistificação na sua poesia e da simulação no poeta (MENDES, 1946, p. 3).

\footnotetext{
${ }^{1}$ Confira a catalogação dos textos de Francisco Paulo Mendes na Tese de Doutorado Memórias literárias de Belém do Pará: o grupo dos novos (1946-1952), $2^{\circ}$ v. 291 p,

Tese (Doutorado em Teoria e História Literária). Instituto de Estudos da Linguagem (IEL), Universidade Estadual de Campinas (UNICAMP), Campinas, 2003, de Marinilce Coelho.

Revista Moara, n. 52, jan-jul 2019 ISSN: 0104-0944

Recebido em 12/04/2019 
No dia $1^{\circ}$ de dezembro do mesmo ano, ainda se verificou, na parte do rodapé do jornal, uma seção intitulada, "Poema de Fernando Pessoa", em que foram publicadas cinco composições do bardo português, sem análise deles: "Mar português", "O infante", "De um cancioneiro", "O lago" e "Marinha".

De Fernando Pessoa houve também, na seção "Divulgação" da Revista Encontro, que teve apenas um número, no segundo trimestre de 1948 e assinada por Francisco Paulo Mendes, uma pequena coletânea, com seis poemas, sob o título "Antologia de poemas, de Fernando Pessoa", constituída das seguintes composições: “Autopsicografia" e "Poema” (Fernando Pessoa), "Dos 'Poemas Inconjuntos"” (Alberto Caieiro), “Ode XII”, “Outra Ode” (Ricardo Reis) e “Aniversário" (Álvaro de Campos), acompanhadas de um estudo de Francisco Paulo Mendes, que já o havia publicado no "Suplemento Arte Literatura" da Folha do Norte, no dia 30 de junho de 1946, contento apenas o poema "Aniversário", de Álvaro de Campos. Foi suprimido do artigo da revista uma anotação que estava no Suplemento e a qual transcrevemos a seguir:

Obras: - Em vida, Fernando Pessoa publicou apenas um volume de poesia, "Mensagens". Toda a sua obra poética que se encontrava dispersa pelos jornais e pelas revistas em que colaborou, foi editada por amigos, em vários volumes com o título de "Obras completas" (MENDES, 1946, p. 3).

Tais informações demonstraram que poemas de Fernando Pessoa foram lidos e discutidos no Pará por iniciantes nas letras, como os quatro amigos poetas que publicavam também no Suplemento: Benedito Nunes, Haroldo Maranhão, Max Martins e Mário Faustino, que tinham o Professor Francisco Paulo Mendes como mediador intelectual. O encarte literário da Folha do Norte configurou um importante material de estudo, haja vista que naquela época as obras do autor luso ainda eram escassas no Brasil e não estavam disponíveis nas escolas do Pará. Contudo, por meio do referido docente, eles tiveram acesso ao material e se projetaram anos depois nas letras nacionais, deixando livros publicados.

Max Martins acrescentou ainda que muito do que foi realizado inicialmente naquela década e posteriormente, em termos de publicações literárias e mudanças na cultura belenense, surgiu de semelhantes encontros lítero-culturais dos jovens com o mestre Francisco Paulo Mendes. De acordo as informações daquele poeta:

Dali nasceu a criação das revistas Encontro, Norte e Cine-Clube Expectadores, o Norte Teatro Escola, a seção local da Associação Brasileiros de Escritores do clube G. K. Chesterton. Ali discutíamos a poesia brasileira: Drummond, Bandeira, Jorge de Lima, Cecília Meireles, Guimarães Rosa, Clarice Lispector. Mas também Rimbaud, Beaudelaire, Saint John Perse, 
Apollinaire, Sartre, Camus, a liberdade, o existencialismo, João Cabral, Fernando Pessoa, Lorca, Picasso, Matisse, Chagall, Klee, Camões, e etc (MARTINS, 2001, p, 76).

As publicações do vate português no citado jornal e na Revista Encontro demonstraram que, no Pará desde 1946, os seus citados literatos estavam lendo a obra de Fernando Pessoa sistematicamente, mediante os poemas selecionados por Francisco Paulo Mendes e que republicamos neste artigo, como expressão de um grande autor da nossa língua portuguesa, publicado no Pará naquele período. Eis, da lavra do poeta luso, algumas composições lidas:

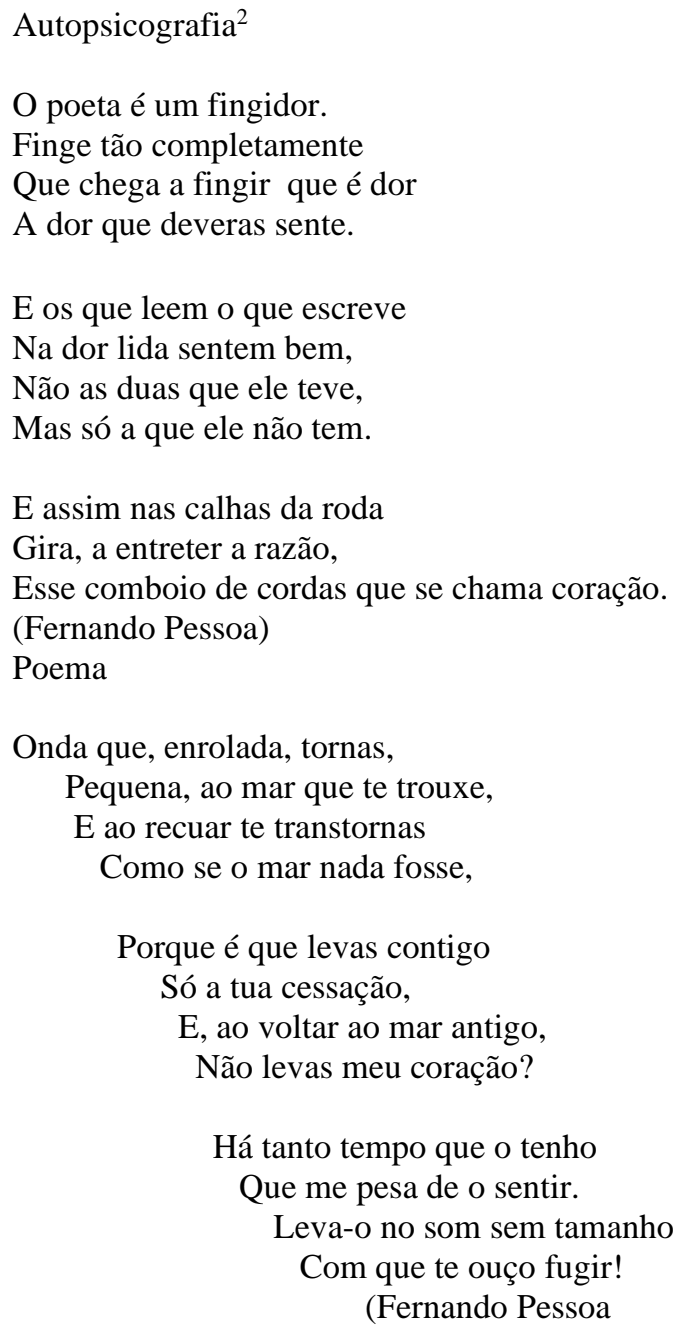

Dos 'Poemas Inconjuntos'

Se, depois que eu morrer, quiserem escrever minha biografia.

Não há nada mais simples.

Tem só duas datas - a da minha nascença e a da minha morte.

Entre uma e outra coisa todos os dias são meus.

Sou fácil de definir.

Vi como um danado.

Amei as coisas sem sentimentalidade nenhuma.

\footnotetext{
${ }^{2}$ A ortografia dos poemas foi atualizada pelo novo acordo ortográfico vigente no Brasil 
Nunca tive um desejo que não pudesse realizar, porque nunca ceguei. Mesmo ouvir nunca foi para mim senão um acompanhamento de ver.

Compreendi que as coisas são reais e todas deferentes umas das outra:

Compreendi isto com os olhos, nunca com o pensamento.

Compreender isto com o pensamento seria acha-las todas iguais.

Um dia deu-me o sono como qualquer criança.

Fechei os olhos e dormi.

Além disso, fui o único da Natureza.

Ode XII

\section{Alberto Caieiro}

A flor que és, não a que dás, eu quero.

Porque me negas o que o que te não peço

Tempo há para negares

Depois de teres dado.

Flor, sê flor! Se te colher Avaro

A mão de infausta esfinge, tu perene

Sombra errará absurda,

Buscando o que não deste.

Outra Ode

Ricardo Reis

Quando, Lídia, vier o nosso outono

Com o inverno que há nele, reservemos

Um pensamento, não para a futura

Primavera, que é de outrem,

Nem para o estio, de quem somos mortos,

Senão para o que fica do que passa

$\mathrm{O}$ amarelo atual que as folhas vivem

$\mathrm{E}$ as torna diferentes

Aniversário

Ricardo Reis

No tempo em que festejavam o dia dos meus anos,

Eu era feliz e ninguém estava morto.

Na casa antiga, até eu fazer anos era uma tradição de há séculos,

$\mathrm{E}$ a alegria de todos, e a minha, estava certa com uma religião qualquer.

No tempo em que festejavam o dia dos meus anos,

Eu tinha grande saúde de não perceber coisa nenhuma.

De ser inteligente para entre a família,

E de não ter as esperanças que os outros tinham por mim.

Quando vim a ter esperança, já não sabia ter esperança.

Quando vim olhar para a vida, perdera o sentido da vida.

Sim, o que fui de suposto a mim mesmo,

O que fui de coração e parentesco,

O que fui de serões de meia província,

O que fui de amarem-me e eu ser menino,

O que fui - ai meu Deus, o que só hoje sei que fui...

A que distância!...

(Nem o acho...)

No tempo em que festejavam o dia dos meus anos!

O que eu sou hoje é como a umidade no corredor do fim da casa, Pondo grelado nas paredes...

O que eu sou hoje (e a casa dos que me amaram treme através das [minhas lágrimas, 
O que eu sou hoje é terem venderem a casa,

É terem morrido todos,

É estar eu sobrevivente a mim mesmo como um fósforo frio...

No tempo em que festejavam o dia dos meus anos...

Que meu amor, como uma pessoa, esse tempo!

Desejo físico da alma de se encontrar ali outra vez,

Por uma viagem metafísica e carnal,

Com uma dualidade de eu para mim..

Comer o passado como pão de fome, sem tempo de manteiga nos [dentes!

Vejo tudo outra vez com uma nitidez que me cega para o que há aqui...

A mesa posta com mais lugares, com melhores desenhos na louça, com [mais copos,

O aparador com muitas coisas - doces, frutas, o resto na sombra [debaixo do alçado -

As tias velhas, os primos diferentes, e tudo era por minha causa,

No tempo em que festejavam o dia dos meus anos...

Para, meu coração!

Não penses! Deixa o pensar na cabeça!

Ó meu Deus, meu Deus, meu Deus!

Hoje já não faço anos.

Duro.

Somam-se-me dias.

Serei velho quando o for.

Mais nada.

Raiva de não ser ter trazido o passado roubado na algibeira!...

O tempo em que festejavam o dia dos meus anos!... $45)$.

Álvaro de Campos (MENDES, 1948, p. 41-

\section{Benedito Nunes e o estudo de obras de Fernando Pessoa}

Após o encerramento do "Suplemento Arte Literatura" do jornal Folha do Norte, em 14 de janeiro de 1951, Benedito Nunes que vinha estudando Fernando Pessoa desde 1946, passou a escrever a respeito do poeta lusitano, publicando no dia 9 de janeiro de 1956 o artigo "Fernando Pessoa - poeta metafísico", no "Suplemento Dominical" carioca do Jornal do Brasil, e inaugurou a sua coluna ali naquela data. O seu segundo artigo, "O homem e sua hora", sobre a composição de Mário Faustino, ele só veio a publicar no dia 5 de agosto de 1956.

Benedito Nunes estampou dois artigos no "Suplemento Magazine" do jornal $A$ Província do Pará, em Belém do Pará: um no dia 23 de fevereiro de 1957, o citado "Fernando Pessoa - poeta metafísico (Introdução de um ensaio)", e "Caieiro - o guardador de rebanho", no dia 31 de março de 1957. Em 1966, passou a dar à luz, na imprensa paulistana, artigos que posteriormente saíram em livros.

Os artigos de Benedito Nunes acerca do poeta português e localizados no "Suplemento Literário" do jornal O Estado de São Paulo foram publicados na seguinte ordem cronológica: "A prosa de Fernando Pessoa", em 1\%10/1966; "O ocultismo na Revista Moara, n. 52, jan-jul 2019 ISSN: 0104-0944

Recebido em 12/04/2019 
poesia de Fernando Pessoa", em 22/10/1966; "Paradoxo e verdade", em 12/11/1966; e "Páginas íntimas de Fernando Pessoa", em 11/1/1967. Tais artigos foram republicados em 1969 no livro nuniano $O$ dorso do tigre, com exceção de "Páginas íntimas de Fernando Pessoa", e com o acréscimo do capítulo "Os outros de Fernando Pessoa", que não foi encontrado em jornal, mas correspondeu ao primeiro capítulo na parte que expõe a obra do vate luso.

O livro $O$ dorso do tigre foi dividido em duas partes: sendo a primeira constituída por capítulos a respeito de filosofia. A segunda parte constituiu-se de artigos sobre os ficcionistas Clarice Lispector e Guimarães Rosa, bem como sobre os poetas Fernando Pessoa e João Cabral de Melo Neto. Como vimos, todos estes autores, que iniciaram suas publicações no "Suplemento Arte Literatura" do jornal Folha do Norte, eram lidos por intelectuais de Belém.

Sobre tão diversificada e atualmente reconhecida produção em versos de Fernando Pessoa, o pensador paraense afirmou que, ao lado dela, o seu autor também legou riquíssimos escritos em prosa, acrescentando que foi como ensaísta que o autor lusitano iniciou a sua carreira de literato em Portugal, com o texto "A nova poesia portuguesa", em 1912, quando da sua passagem pelo Saudosismo, movimento estético e literário, religioso e filosófico, de carácter nacionalista, do qual resultou a obra pessoana Mensagem (1934). De acordo as pesquisas nunianas:

\footnotetext{
Muitos, senão a maioria dos textos em prosa, dentre os que se tornaram conhecidos graças a Jorge de Sena, que reuniu no volume Páginas de doutrina estética (1946), tem valor autônomo independentemente das relações que podem ter e que efetivamente têm com a parte poética da obra de Fernando Pessoa (NUNES, 2009, p. 247).
}

Benedito Nunes, ao estudar a obra de João Cabral de Melo Neto num livro da sua autoria, o volume I da coleção Poetas modernos do Brasil (1971), declarou que Fernando Pessoa, notadamente quando despontou a sua vasta obra póstuma, em 1942, foi muito importante no Brasil para a Geração de 45, à qual perteceu, entre outros, o poeta pernambucano, marcando "não só o lirismo moderno na literatura portuguesa, como também uma metodologia de criação literária, que substitui o princípio da sinceridade biográfica pelo princípio da sinceridade artística” (NUNES, 1971, p. 26-27).

\section{Considerações finais}

Como registramos, Fernando Pessoa se revelou um poeta importante para a formação dos literatos do Pará, a exemplo de Benedito Nunes, Haroldo Maranhão, Max 
Martins e Mário Faustino, os quais, para sistematizar as suas pesquisas estéticas, se agruparam em torno do docente Francisco Paulo Mendes, mentor de tais estudiosos que com ele se aperfeiçoaram, vindo mais tarde a serem autores em prosa e verso.

Benedito Nunes, que, particularmente, se tornou um crítico literário e intérprete de filosofia reconhecido nacionalmente, continuou o trabalho iniciado pelo mestre Francisco Paulo Mendes nos idos de 1946. Noutra formulação, continuou estudando e publicando artigos e livros, entre outros, sobre o poeta Fernando Pessoa.

\section{REFERÊNCIAS}

ABREU, Paulo Plínio. Poesia. Org. Francisco Paulo Mendes, Belém: Universidade Federal do pará, 1978.

MARTINS, Max. Por ouvir dizer. In. O amigo Chico: fazedor de poetas. Org, Benedito Nunes. Belém: SECULT, 2001, p. 75-77.

MENDES. Francisco Paulo. Da caridade e da liberdade no mundo cristão de apósguerra. Folha do Norte. Belém, ano I, No. 2, 19 de maio de 1946, Suplemento Arte Literatura, p. 1-3.

Escritores portugueses: José Régio. Folha do Norte. Belém, 16 de junho de 1946, Suplemento Arte Literaturall, No 5, p. 3. 3.

Escritores portugueses contemporâneos: Fernando Pessoa. Folha do Norte. Belém, 30 de junho de 1946, Suplemento Arte Literatura, No 6, p. 3.

Escritores portugueses Contemporâneos: Florbela Espanca (18941930)\|. Folha do Norte. Belém, 14 de julho de 1946, Suplemento Arte Letras, №. 7, p. 3.5.

Escritores portugueses Contemporâneos: Alberto de Serpa. Folha do Norte.

Belém, 28 de julho de 1946, Suplemento Arte Literaturall, No 8, p. 3. 6.

Escritores portugueses Contemporâneos: Antônio Feijó (1862-1917). Folha do

Norte. Belém, 7 de setembro de 1946, Suplemento Arte Literatura, No 11, p. 3. 7.

Ressurreição e vida. Folha do Norte. Belém, No. 23, 30 de março de 1947, Arte Suplemento Literatura, p. 1. 8.

"Notas para uma conferência sobre a poesia contemporânea. (Especial para a

Folha do Norte). Rio. Folha do Norte. Belém, No 28, $1^{\circ}$ de junho de 1947, Suplemento Arte Literatura, p. 1-6. 9.

Notas para uma conferência sobre a poesia contemporânea. (Especial para a 
Folha do Norte). Jornal Folha do Norte. Belém, № 31, 22 de junho de 1947, Suplemento Arte Literatura, p. 3. 10.

O Poeta e a rosa. Folha do Norte. Belém, № 76,25 de abril de 1948, Suplemento Arte Literatura, p. 1-3. 11.

Leconte de Lisle e a poesia Francesa do Século XIXIl. Folha do Norte. Belém, $1^{\text {o }}$ de janeiro de 1949, Suplemento Arte Literaturall, No .108 , p. 1-4-2.

Apresentação. In. Obras completas.3v. de Bruno Menezes. Belém: Secretaria Estadual de Cultura e Conselho Estadual de Cultura do Pará, 1993

NASCIMENTO, Maria de Fatima do. Benedito Nunes e a moderna crítica literária Brasileira (1946-1969), v. I, 2012, 343 p. Tese (Doutorado em Teoria e História Literária) - Instituto de Ensino da Linguagem (IEL), Universidade Estadual de Campinas (UNICAMP), São Paulo, 2012.

. Benedito Nunes e a moderna crítica literária Brasileira (1946-1969), v. II, Anexos/Acervos, 2012, 579 p. Tese (Doutorado em Teoria e História Literária) Instituto de Ensino da Linguagem (IEL), Universidade Estadual de Campinas (UNICAMP), São Paulo, 2012.

NUNES, Benedito. Fernando Pessoa - poeta metafísico. Jornal do Brasil. Rio de Janeiro, 9 jan. 1956. Suplemento Dominical, p.

Fernando pessoa: poeta metafísico (Introdução de um ensaio). A Província do Pará. Belém, 24 fev. 1957, Letras e Artes, Folhetim de Crítica, p. 2.

Caieiro, o guardador de rebanho. A Província do Pará. Belém, 31 mar. 1957, Suplemento Magazine, p.1.

A prosa de Fernando Pessoa. O Estado de São Paulo. São Paulo, 1ºut. 1966. Suplemento Literário, p. 6.

. O ocultismo na poesia de Fernando Pessoa. O Estado de São Paulo. São Paulo, 22 out. 1966. Suplemento Literário, p. 1.

. Paradoxo e verdade. O Estado de São Paulo. São Paulo, 12 nov. 1966, Suplemento Literário, p.1. O dorso do tigre. São Paulo: São Paulo: Ática, 2009.

João Cabral de Melo Neto. (Coleção Poetas Modernos do Brasil/1). Petrópolis: Editora Vozes Ltda/Instituto Nacional do livro, 1971.

PESSOA, Fernando. Poemas de Fernando Pessoa. Org. Francisco P. Mendes. Folha do Norte. Belém, $1^{\text {o }}$ de dezembro de 1946, Suplemento Arte Literatura, Ano I, No 16, p. 4. 